\title{
SYNTHETIC NATURAL GAS PRODUCTION: PRODUCTION COST, KEY COST FACTORS AND OPTIMAL CONFIGURATION
}

\author{
DEVASANTHINI DEVARAJ ${ }^{1,2}$, EOIN SYRON $^{1,2} \&$ PHILIP DONNELLAN $^{1}$ \\ ${ }^{1}$ School of Chemical \& Bioprocess Engineering, University College Dublin, Ireland \\ ${ }^{2}$ UCD Energy Institute, University College Dublin, Ireland
}

\begin{abstract}
The volatile nature of the renewable energy sources requires energy storage to compensate for the imbalances and to provide reliable base load. Power-to-Methane technology facilitates long-term high capacity renewable energy storage in the form of Synthetic Natural Gas (SNG) in the gas network. Unlike hydrogen, SNG usage in the network has no restrictions and natural gas appliances can operate on SNG. The two inputs required to produce $\mathrm{SNG}$ in the methanator are hydrogen and $\mathrm{CO}_{2}$ and they can be obtained from several sources. This leads to multiple possible process flow configurations in SNG production, each of them with varying performance. An optimization model has been developed in GAMS to analyse the performance of these various configurations. The objective of this research is to determine the optimal configuration, key cost factors and their effects on the production cost to identify the areas that require further development for cost reduction. This work also aims to determine the production cost per unit of SNG and the factors with most significant influence on the production cost by implementing a factorial design and a multivariate analysis (analysis of variance) approach. Methanator, electrolyser, biogas upgrader and hydrogen storage are considered as the fundamental process units in this work. The lowest production cost identified in the first year of production is 0.432 $€ / \mathrm{kWh}_{\mathrm{SNG}}$. The discounted production cost obtained shows that the lowest cost in 20 years from now is $0.143 \mathrm{€} / \mathrm{kWh}_{\mathrm{SNG}}$. The variable with the most influence on the production cost is the capex of the methanator followed by the capacity of the methanator.
\end{abstract}

Keywords: Power-to-Methane, SNG production cost, Synthetic Natural Gas (SNG).

\section{INTRODUCTION}

According to COP21, greenhouse gas emissions need to be reduced by at least $40 \%$ by 2030 (from 1990 levels). The key components that help to achieve this target are renewable energy sources, energy efficiency and carbon capture and storage (CCS) [1]. A target of 20\% renewable energy in the overall energy mix by 2020 is proposed by the European Commission [2] To achieve the renewable and emission reduction targets, many countries are increasingly investing in renewable sources every year. More renewable penetration in the energy mix can be problematic due to their variability and it needs to be balanced to ensure grid stability. The Power-to-Gas (PtG) connects the power grid to other energy sectors such as heat and fuel and could play a vital role in tackling the variability of renewable energy [3, 4]. PtG converts the surplus power into hydrogen or Synthetic Natural Gas (SNG), which can be injected into the existing natural gas network.

Recycling $\mathrm{CO}_{2}$ into SNG is an important step to achieve complete decarbonization of the energy sector [5]. Due to gas sector decarbonization, gas networks in the future may diversify in their business by transporting gas types like hydrogen, SNG or $\mathrm{CO}_{2}$ [6]. However, transporting various gases in the network have implications for its operation due to their influence on the gas quality. Hydrogen has a lower energy density compared with that of natural gas and there are restrictions to the amount of hydrogen that can be injected directly into the gas network [7]. The usage of SNG in the network is advantageous as it is identical to natural gas 
and is compliant with all network devices. Also, a large amount of SNG can be stored in the gas network which prevents the construction of additional storage facilities [5].

\subsection{Power-to-Gas technology}

The first step in PtG is electrolysis, where an electrolyser connected to the electric grid produces hydrogen and oxygen by splitting water (Equation 1). Two types of electrolysers are available on an industrial scale in the market currently: alkaline electrolysers and polymer electrolyte membrane electrolysers. Solid oxide electrolysis is not considered in this work as it is currently at research and development scale. The next step is methanation, where the hydrogen reacts with $\mathrm{CO}_{2}$ to produce methane. There are two types of methanation: catalytic and biological. The reaction that occurs in catalytic methanation is called the Sabatier process (Equation 2). In biological methanation, archaea (a group of microorganisms) convert $\mathrm{CO}_{2}$ and hydrogen to methane.

$$
\begin{gathered}
\mathrm{H}_{2} \mathrm{O} \rightarrow \mathrm{H}_{2}+1 / 2 \mathrm{O}_{2} \\
\mathrm{CO}_{2}+4 \mathrm{H}_{2} \rightarrow \mathrm{CH}_{4}+2 \mathrm{H}_{2} \mathrm{O}
\end{gathered}
$$

The main application for PtG is the injection of hydrogen or SNG into the natural gas network. If the electricity is obtained from renewables, Power-to-Methane (PtM) technology can facilitate large-scale long-term renewable energy storage. The advantage of SNG production over hydrogen is that SNG can be extensively stored and distributed in the existing natural gas network without any restrictions.

\subsection{Sources of hydrogen and $\mathrm{CO}_{2}$}

Hydrogen can be mainly obtained from water splitting in electrolysers from potentially excess renewables or electricity from the grid. The variability of renewable energy causes fluctuations in electrolyser operation and may require hydrogen storage. Hydrogen can be stored in multiple ways such as a pressurized gas, a liquid or absorbed in hydrides. The best option for temporary hydrogen storage is high pressured gas tanks [2].

In general, biogas from anaerobic digestion is regarded as the main $\mathrm{CO}_{2}$ source as the PtG requires small carbon sources [2]. Biogas is composed of methane (50-70\%), $\mathrm{CO}_{2}(30-50 \%)$ and small amounts of $\mathrm{H}_{2} \mathrm{~S}$, mercaptans and siloxanes [2]. Biogas itself does not meet the gas network specifications and needs to be upgraded (remove $\mathrm{CO}_{2}$ ) to be injected into the gas network. This is done by several techniques such as Pressure Swing Adsorption, amine absorption and water scrubbing [8]. The $\mathrm{CO}_{2}$ stream from the biogas upgraders is usually vented or disposed of. This can act as a potential $\mathrm{CO}_{2}$ source for the methanator and it also eliminates the problem of disposal or storage of $\mathrm{CO}_{2}$.

\subsection{Overview of researches in PtG plant optimization}

Several researchers have investigated optimizing a PtG plant. Blanco et al. reported that high biomass potential and CCS can lower the system cost in PtM deployment [9]. Sibai et al. optimized the reactor section of the Sabatier process in an attempt to reduce the SNG production cost [10]. An overview of the production costs of SNG in 2030 and 2050 is provided by 
Gorre et al. [11]. They reported that the production costs are mainly influenced by electricity prices and the operating hours of the electrolyser and methanator [11].

Jeanmonod et al. investigated SOCE-based PtM systems for large-scale renewable energy storage and biogas upgrading [12]. They proposed design concepts (with $\mathrm{H}_{2} / \mathrm{CO}_{2} / \mathrm{Biogas}$ buffers) to determine the system performance and to compare the technology readiness, capacity and cost of each gas storage [12]. Naturgy developed a pilot plant to produce SNG by adding hydrogen to biogas from anaerobic digestor under industrially relevant conditions and eventually proposed SNG as an alternative to the use of biogas in combined heat and power generation units [13].

A techno-economic analysis was carried out on the continuous and intermittent operation of three configurations of biomethane production $\left(\mathrm{CH}_{4}\right.$ from biogas upgrading, $\mathrm{CH}_{4}$ from methanation after biogas upgrading and $\mathrm{CH}_{4}$ from methanation without biogas upgrading) [9]. This work identified that the methanator needs to be operated for longer when the electricity prices are high in order for the produced gas to be competitive. Bailera et al. reviewed $\mathrm{PtG}$ technologies and projects existing worldwide [15]. An exceptional increase in PtG deployment started after 2010 and it is expected to last at least until 2025. Currently, the cost of SNG is estimated to be 70-125 €/MWh [3], which is up to seven times that of the natural gas. In order to compete with natural gas, the price of SNG must be reduced to at least $40 € /$ $\mathrm{MWh}$. The economic viability of SNG production from $\mathrm{CO}_{2}$ capture and usage identified that further research and development is required on electrolyser efficiency and capex of the methanator [3]. The SNG production process is subjected to high operating hours and it appears to be more economic when operated as a continuous or seasonal production process rather than for intermediate storage [3].

\subsection{Description of the SNG production process flow}

The main components in the SNG production process flow are the electrolyser, hydrogen storage, biogas upgrader and methanator. These units are available in various capacities, efficiencies and a range of investments. The $\mathrm{CO}_{2}$ sources considered in this work are $\mathrm{CO}_{2}$ from the biogas upgrader, biogas and external $\mathrm{CO}_{2}$ storage. Hydrogen is obtained from an electrolyser or hydrogen storage. The multiple process flow combinations in SNG production are shown in Fig. 1. The objective of this work is to identify the optimal process flow configuration in the SNG production process, which is to determine which hydrogen source and $\mathrm{CO}_{2}$ source combination will yield the minimum production cost based on the efficiency, capex, opex, demand and the year of operation. It also focuses on identifying the most significant cost factors in SNG production. An optimization model to investigate the performance of the various process configurations has been developed.

\subsubsection{Fundamentals of the parameters involved in the process flow}

The efficiency, capacity, capital expenditure (capex), operational and maintenance expenses (opex) and the lifetime of each of these units are required for the analysis of the system. The values for these parameters are obtained from multiple sources and Table 1 represents the range of costs used in the model for selected parameters. Even though the capex of PtG systems is very high currently, a decreasing trend in cost is expected [16] due to improvements in manufacturing methods and performance. The operational expenses (opex) are of two kinds: fixed and variable. Fixed opex is independent of the operational time of the units. They include scheduled maintenance, insurance, occupancy costs, etc. 


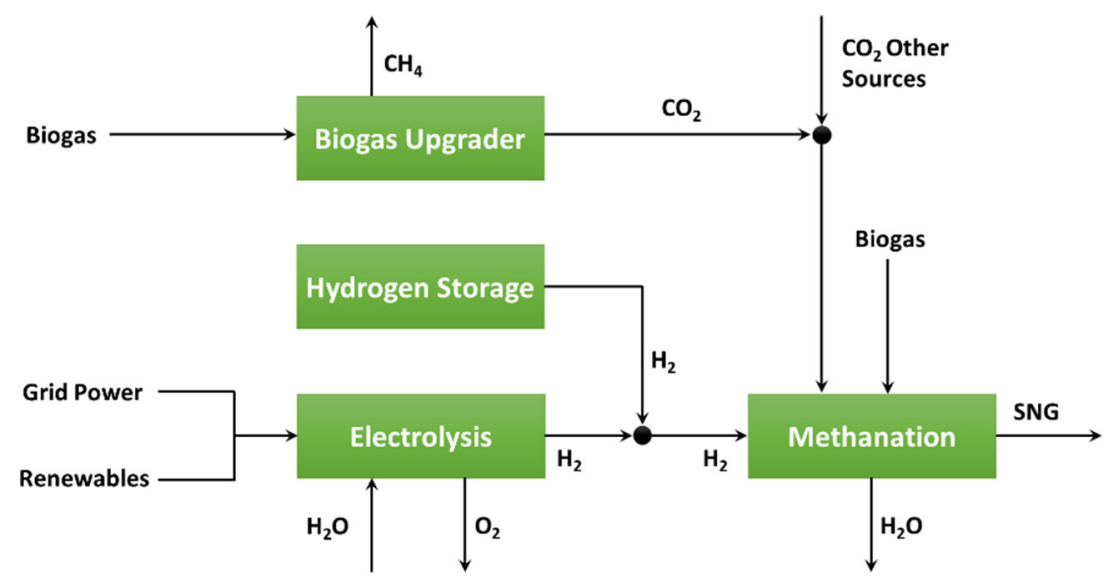

Figure 1: Process flow configuration of Synthetic Natural Gas production.

Table 1: Range of costs used in the model for selected parameters.

\begin{tabular}{llll}
\hline Category & Range of Costs & Unit & Sources \\
\hline Capex & & & \\
Methanation (M) & $300-1500$ & $€ / \mathrm{kW}_{\mathrm{SNG}}$ & {$[2]$} \\
Electrolyser (E) & $220-955$ & $€ / \mathrm{kW}_{\mathrm{H} 2}$ & {$[2,16]$} \\
Biogas upgrader $(\mathrm{BGU})$ & $15-25$ & $\mathrm{cent} / \mathrm{m}^{3}$ & {$[17]$} \\
Hydrogen storage $\left(\mathrm{H}_{2} \mathrm{St}\right)$ & $3.8362-8$ & $€ / \mathrm{kg}$ & {$[11]$} \\
Purchase price & & & \\
Biogas & $0.22-0.47$ & $€ / \mathrm{kg}$ & {$[18]$} \\
Hydrogen & $2-2.67$ & $€ / \mathrm{kg}_{\mathrm{H} 2}$ & {$[19]$} \\
Electricity purchased & $9.78-17.56$ & $c e n t / \mathrm{kWh}$ & {$[18]$} \\
Selling price & & & \\
Synthetic Natural Gas & $16.5-39.2$ & $c e n t / \mathrm{kWh}_{\mathrm{SNG}}$ & {$[2]$} \\
Oxygen & $4.8-11$ & $c e n t / \mathrm{kg}$ & {$[20,21]$} \\
\hline
\end{tabular}

They usually range from $1 \%$ to $5 \%$ of the capex and can vary depending on the individual unit in the PtG plant. They are expressed in $€ / \mathrm{a}$. Variable opex depends on the system output, plant utilization, raw materials, etc., and they are expressed in $€ / \mathrm{kWh}$. The water input to the electrolyser and $\mathrm{CO}_{2}$ from external sources to the methanator are assumed to be available for free. Heat recovery from electrolyser and methanator unit operations is not considered in the model.

\section{METHODOLOGY}

The algorithm followed in developing the model to determine the process flow configuration to yield the minimal production cost and key cost factors is described below. 
1. Deciding and defining the variables required - This method uses three kinds of variables: independent, dependent and binary. The capex, opex, purchase price of biogas, electricity and hydrogen (for independent hydrogen storage) and efficiency of all the process units are defined as independent variables (IVs). The production price per $\mathrm{kWh}_{\mathrm{SNG}}$ is the only dependent variable. A set of binary variables is used to determine the optimal process flow, where 0 and 1 denote the absence and existence of a specific unit, respectively.

2. Planning the equations - The equations to define the multiple process flows are decided. They are the mass balance equations and input and output streams for each of the units are represented in Fig. 1 (examples given in Equations 3 and 4).

$\mathrm{H}_{2}$ input to Methanator $(\mathrm{kg})=\mathrm{H}_{2}$ from Electrolyser $(\mathrm{kg})+\mathrm{H}_{2}$ from Storage $(\mathrm{kg})$

$$
\mathrm{CO}_{2}(\mathrm{~kg})+0.182 * \mathrm{H}_{2}(\mathrm{~kg})=0.364 * \mathrm{CH}_{4}(\mathrm{~kg})+0.818 * \mathrm{H}_{2} \mathrm{O}(\mathrm{kg})
$$

3. Objective function - The objective of this method is to obtain the minimized production cost per unit of SNG produced (given in Equation 5).

$$
\text { Production Cost }=\frac{\sum_{\mathrm{t}=1}^{\mathrm{n}} \operatorname{Capex}_{\mathrm{t}}+\text { Opex }_{\mathrm{t}}+\text { Purchase Price }_{\mathrm{t}} /(1+\mathrm{r})^{\mathrm{t}}}{\mathrm{SNG}_{\mathrm{t}}}
$$

where Capex $\mathrm{t}_{\mathrm{t}}$ is the capital expenditure, Opex $\mathrm{t}_{\mathrm{t}}$ the operational costs, Purchase Price $\mathrm{t}_{\mathrm{t}}$ the purchase price of input streams (biogas, $\mathrm{CO}_{2}$ and power), $\mathrm{SNG}_{\mathrm{t}}$ the amount of $\mathrm{SNG}$ produced, $\mathrm{r}$ the discount factor ( $6 \%$ for all costs) [11] and $t$ is the year.

4. Deciding the constraints for the process flow - The constraints required to solve the objective function are defined. They are the demand constraint (to specify the minimum amount of SNG required to be produced in a year), logical constraints to assigning values to the binary variables (to indicate the presence of each unit in the optimal process) and capacity constraints (examples given in Equations 6, 7 and 8).

$$
\begin{array}{cc}
\text { demand.. } & \text { SNG.lo = 'value'; } \\
\text { logic1.. } & \mathrm{H}_{2} \mathrm{E} \rightarrow \mathrm{H}_{2} \text {.up *y1; } \\
\text { capacity.. } & \mathrm{SNG}_{\text {out }} \leq \text { MethanatorCapacity; }
\end{array}
$$

where SNG.lo is the lowest allowed value of SNG output, $\mathrm{H}_{2} \mathrm{E}$ the hydrogen from electrolyser and $\mathrm{y} 1$ is the binary variable denoting the existence of electrolyser in the process flow.

5. Solving the objective function - The optimization problem consists of one dependent variable and many IVs. Each of the IVs holds a range of values. For example, electrolyser capex is an IV and it can be of any value between 220 and $955 € / \mathrm{kW}$. Due to the nature of the problem, a factorial design concept is used, where one minimum value and one maximum value are used for each of the IVs. The objective function is solved multiple times for all combinations of values of IVs (Snippet of the input is given in Table 2).

6. Multivariate analysis of the output - The optimal configuration and production cost per $\mathrm{kWh}_{\mathrm{SNG}}$ for each combination is obtained (Snippet of the output is given in Table 2). One-factor analysis of variance (ANOVA) is performed to determine whether the IVs have a significant influence on the production cost and this subset of IVs obtained represents the key cost factors. Factorial ANOVA is performed on the subset of IVs to identify 
Table 2: Sample input (capex, opex, efficiency and capacity) to solve the objective function and the respective outputs (production cost and optimal process flow). Units for capex values are given in Table 1 . Opex values are in $€ / \mathrm{kW}$, capacity is in $\mathrm{kW}$ and cost is in $€ / \mathrm{kWh} .0 \mathrm{~s}$ and $1 \mathrm{~s}$ for $\mathrm{M}, \mathrm{E}, \mathrm{BGU}, \mathrm{H}_{2} \mathrm{St}$ and $\mathrm{CC}$ indicate the presence/absence of the respective units in the optimized process flow.

\begin{tabular}{c|c|c|c|c|c|c|c|c|c|c|c|c|c|c|c|c|c|c|c|c|c|c|c|}
\hline \multirow{2}{*}{ Year } & \multicolumn{4}{|c|}{ Capex } & \multicolumn{4}{c|}{ Opex } & \multicolumn{2}{c|}{ Efficiency } & \multicolumn{3}{c|}{ Capacity } & \multirow{2}{*}{ Cost } & \multirow{2}{*}{ M } & \multirow{2}{*}{ BGU } & \multirow{2}{*}{ E } & \multirow{2}{*}{ H$_{2}$ St CC } \\
& $\mathrm{M}$ & $\mathrm{E}$ & $\mathrm{BGU}$ & $\mathrm{H}_{2} \mathrm{St}$ & $\mathrm{M}$ & $\mathrm{E}$ & $\mathrm{BGU}$ & $\mathrm{H}_{2} \mathrm{St}$ & $\mathrm{M}$ & $\mathrm{E}$ & $\mathrm{M}$ & $\mathrm{E}$ & & & & & & \\
\hline 1 & 300 & 220 & 15 & 3.84 & 4.5 & 3.3 & 0.002 & 0.058 & 0.7 & 0.65 & 130 & 170 & 0.533 & 1 & 0 & 1 & 0 & 1 \\
\hline 1 & 300 & 220 & 15 & 3.84 & 4.5 & 3.3 & 0.002 & 0.160 & 0.7 & 0.65 & 130 & 500 & 0.531 & 1 & 1 & 1 & 0 & 0 \\
\hline 1 & 300 & 220 & 15 & 3.84 & 4.5 & 3.3 & 0.004 & 0.160 & 0.7 & 0.65 & 500 & 500 & 0.672 & 1 & 1 & 1 & 0 & 0 \\
\hline$:$ & $:$ & $:$ & $:$ & $:$ & $:$ & $:$ & $:$ & $:$ & $:$ & $:$ & $:$ & $:$ & $:$ & $:$ & $:$ & $:$ & $:$ & $:$ \\
\hline 20 & 1500 & 955 & 25 & 8 & 30 & 19.1 & 0.004 & 0.160 & 0.8 & 0.78 & 500 & 500 & 0.526 & 1 & 1 & 0 & 1 & 0 \\
\hline
\end{tabular}

the existence of an interactive effect between the variables and their effect on the production cost.

\section{RESULTS AND DISCUSSIONS}

The total final consumption of natural gas in Ireland in 2017 was 1824 ktoe [22] and 5\% of gas demand is assumed to be the minimum amount of SNG to be generated per year which is $70,000 \mathrm{~kg}$. The objective function is solved for multiple combinations of values of IVs $(49,116$ runs) and in each run, an optimal process flow configuration and SNG production cost per kWh are identified (Table 2).

The lowest production cost per kWh of SNG produced in year 1 is $€ 0.432$ and the optimal process configuration used hydrogen from electrolyser and $\mathrm{CO}_{2}$ stream from biogas upgrader as the sources of hydrogen and $\mathrm{CO}_{2}$, respectively. The highest cost per kWh of SNG in year 1 is $€ 1.959$. This is mainly due to the high capex and opex values of the methanator and the electrolyser. Within the same year, the production cost per unit of SNG decreases when the demand (minimum amount of SNG to be produced) is increased. Figure 2 represents the variation in production cost with respect to demand in year 1 . The production cost can be reduced by maximizing the utilization of methanator capacity and lowering the demand tends

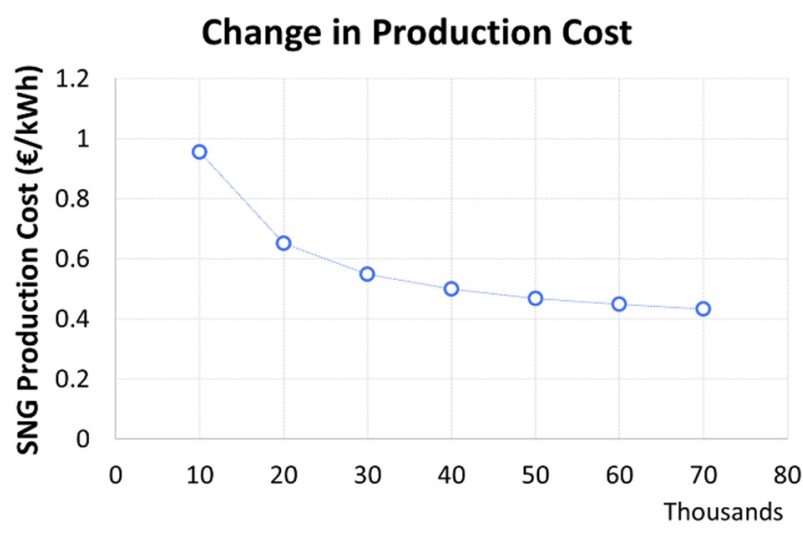

SNG Demand (kg)

Figure 2: Change in Synthetic Natural Gas production costs (year 1) vs demand. 


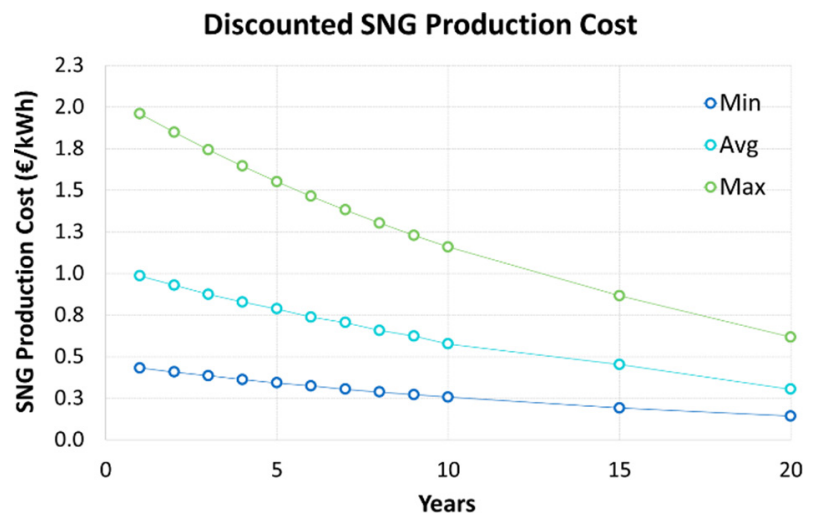

Figure 3: Discounted Synthetic Natural Gas production costs vs time.

to increase the cost. The lifetime of the production setup is assumed to be 20 years [11]. Therefore, the discounted production cost is obtained on a yearly basis for up to 20 years (Fig. 3). On average, the discounted cost drops by $5.62 \%$ every year. The lowest cost in year 20 is $€ 0.143 / \mathrm{kWh}_{\mathrm{SNG}}$ and the highest cost in year 20 is $€ 0.617 / \mathrm{kWh}_{\mathrm{SNG}}$. It may be noted that due to the nature of the discount factor applied, the difference between the highest and the lowest cost is decreasing every year.

It is identified that the electricity prices and oxygen income play a significant role in the production cost. In years 1, 10 and 20 of the production, halving the electricity prices leads to a nearly $25 \%$ decrease in the production cost. If the oxygen generated at the electrolyser is sold at the rate of 4.8 cent $/ \mathrm{kg}$ [20], the production cost per $\mathrm{kWh}_{\mathrm{SNG}}$ is reduced by an average of $3.47 \%$. At the same time, the price of oxygen may be high (up to $11 \mathrm{cent} / \mathrm{kg}$ [21]) if it is used for medical care, which in turn can have a significant impact in terms of the overall cost. The role of oxygen income on the overall production cost is represented in Fig. 4.

Some significant observations regarding the optimal configuration are:

a. Hydrogen from the electrolyser is the preferred source of hydrogen whenever the capacity of the electrolyser is higher.

b. Regardless of the year of production, the lowest production cost per $\mathrm{kWh}_{\mathrm{SNG}}$ is obtained with lower methanator capex and capacity and higher methanator efficiency. The optimal

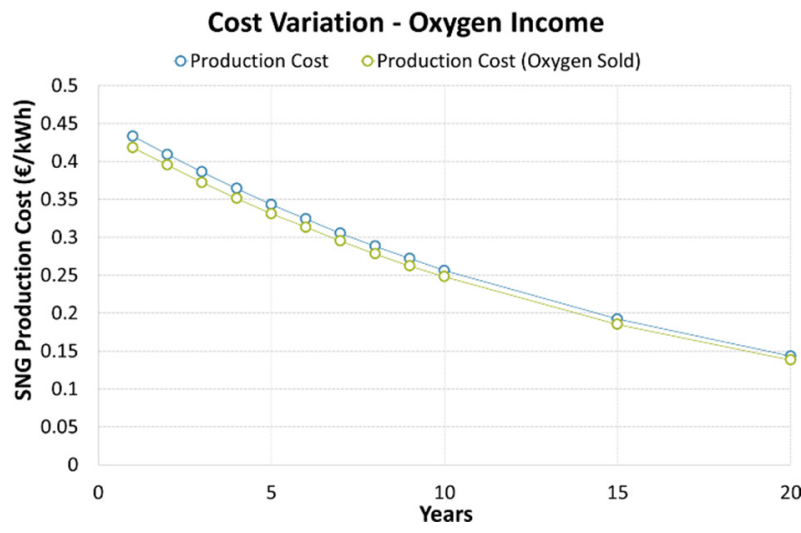

Figure 4: Change in Synthetic Natural Gas production cost with oxygen income. 


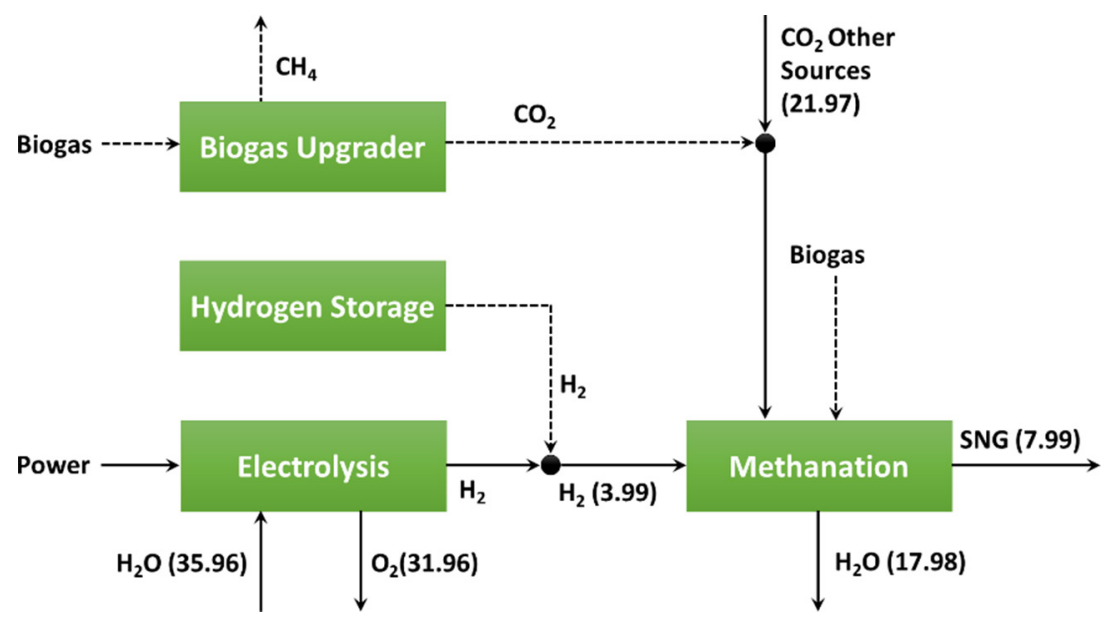

Figure 5: Representation of optimal process flow (solid arrows) configuration in the lowest production cost scenarios. The values of the streams are in $\mathrm{kg} / \mathrm{h}$.

configuration (given in Fig. 5) in these cases used electrolyser as the source of hydrogen and external $\mathrm{CO}_{2}$.

c. In scenarios with high capex and opex of methanator, there is no specific preference observed over the sources of hydrogen or $\mathrm{CO}_{2}$ and the production cost per $\mathrm{kWh}_{\mathrm{SNG}}$ is much higher (around $€ 1.12 / \mathrm{kWh}_{\mathrm{SNG}}$ ).

d. Whenever the efficiency of electrolyser is low and the efficiency of methanator is high, the production cost can be reduced by decreasing the capex and opex of methanator. The rest of the variables have no significant impact on the outcome in these cases.

Due to the nature of the problem, with multiple IVs, it is important to identify the variables that have the most significant influence on the output. This is carried out by performing one-factor ANOVA and the results obtained are provided in Fig. 6. It can be noted that the

\section{Single Factor ANOVA}

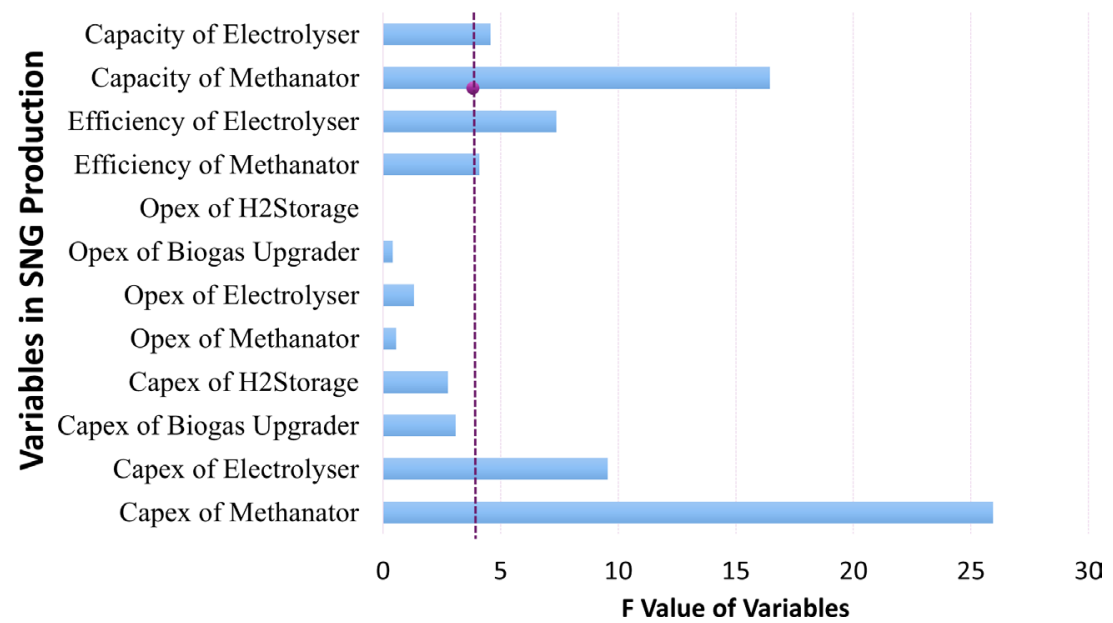

Figure 6: Representation of the main effect of the variables on Synthetic Natural Gas production cost. 


\section{Factorial ANOVA}

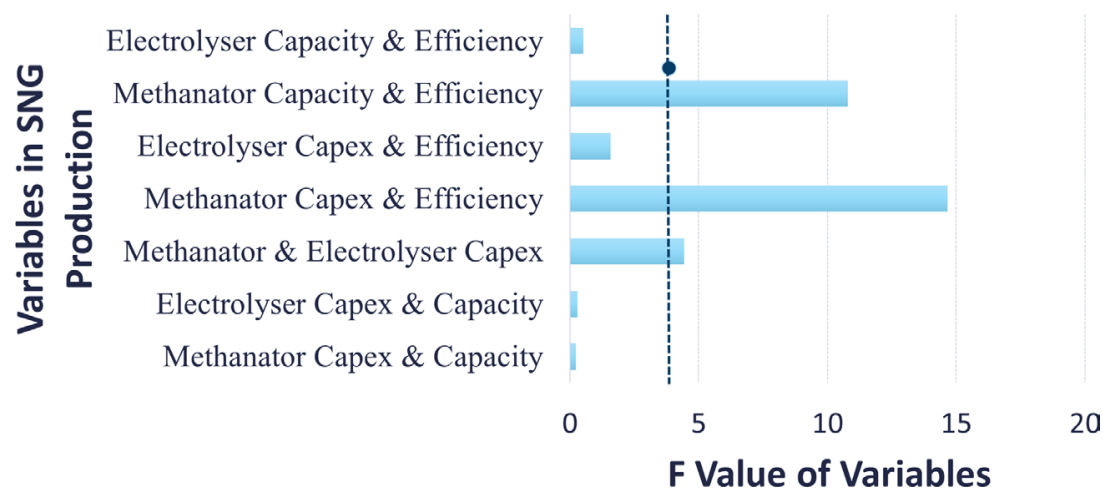

Figure 7: Representation of the interactive effect of the variables on Synthetic Natural Gas production cost.

variable with the most influence on the output is the capex of methanator, followed by the capacity of methanator. This implies that the variation in capex value of methanator can significantly alter the cost per $\mathrm{kWh}_{\mathrm{SNG}}$. It can be noted that the investment for the methanator and the electrolyser and their performance are the driving factors in PtM. The influence of other variables, though existent, is not significant.

As mentioned in Section 1.4.1, the opex values are of two kinds (fixed and variable). Fixed opex values are used in solving the objective function and eventually to perform one-factor ANOVA. When variable opex is used, the variables found to have the most influence on the cost are opex of the methanator and electrolyser. Factorial ANOVA is used to identify the interactive effect between variables, and it is performed over the subset of IVs (from Fig. 6) which had a significant impact on the cost. Factorial ANOVA results are shown in Fig. 7 and the most significant interactions are spotted among the methanator capacity, capex and efficiency emphasizing the fact that methanator investment and performance is the key factor in SNG production.

The interaction between methanator capacity and its efficiency is analysed in detail and is shown in Fig. 8. The minimum capacity required to produce the given demand is found to be

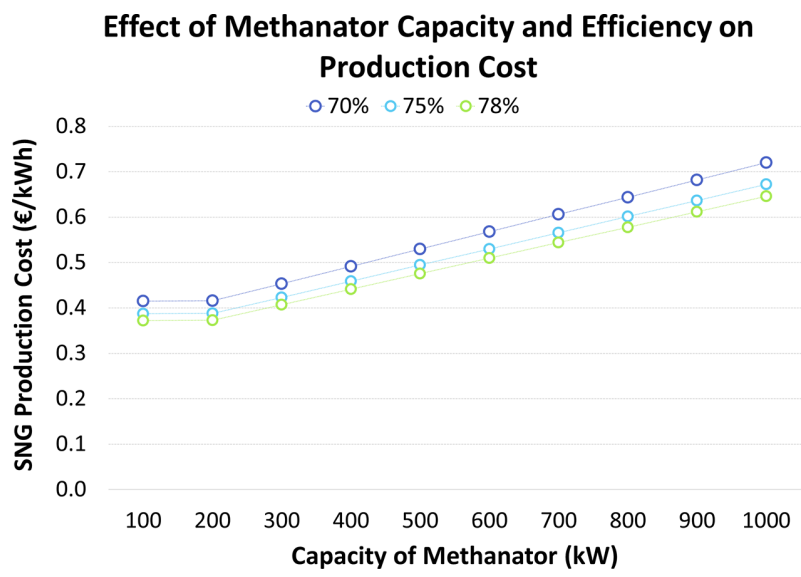

Figure 8: Representation of the interactive effect of the methanator capacity and efficiency on Synthetic Natural Gas production cost (year 1). 
$130 \mathrm{~kW}$. Increasing the size of the methanator unit to produce the same demand results in increased production costs. It can also be seen that the production cost at $100 \mathrm{~kW}$ is as high as the cost at $200 \mathrm{~kW}$. At $100 \mathrm{~kW}$, the SNG produced is less than the given demand and hence the cost per unit of SNG is higher. The same technique can be used to analyse every interactive effect in detail to help process planning and investment.

Having discussed the influential cost factors in SNG production, the revenues of a PtG plant in the future may depend on its $\mathrm{CO}_{2}$ footprint and whether it is green. Also, the natural gas price forecast indicated that there will not be any significant change in gas prices in the future [23]. Hence, it may be required to encourage the use of SNG through measures like carbon pricing and blending requirements.

\section{CONCLUSIONS}

This work determines which conditions yield the minimum production cost per $\mathrm{kWh}_{\mathrm{SNG}}$ by analysing various process flow configurations involved in SNG production. The discounted relative difference in production cost shows that long-term SNG production setup is preferable. When the oxygen income is considered, the production cost per $\mathrm{kWh}_{\mathrm{SNG}}$ decreases by around $3.5 \%$ and hence it appears to be beneficial in terms of cost. The initial production setup and the eventual upgrading of the process units can be determined by knowing the most influential variables, which are identified by the factorial design approach implemented in this work. It has been identified that the production cost can be lowered by reducing the capex of the methanator and by choosing the methanator capacity in accordance with the SNG demand.

Capex values of the PtG technology are relatively high today, but at the same time, a decreasing trend in the capex values is expected due to technological development (to improve efficiencies) and manufacturing practices (standardized sizes and series) [16]. ANOVA results indicate that the key cost factors in long-term SNG production are capex of methanator and electrolyser. The capex values of PtM process units are expected to decrease up to $50 \%$ (especially for methanator and electrolyser which are expected to decrease up to $70 \%$ ) in the year 2050 [11], which can reduce the production cost of SNG to a great extent ensuring that it is competitive with other gas sources like natural gas and biomethane.

\section{REFERENCES}

[1] EU position for the UN climate change conference in Paris: Council conclusions, Conference of the Parties (COP 21), 2015.

[2] Gotz, M., Lefebvre, J., Mors, F., Koch, A.M., Graf, F., Bajohr, S., Reimert, R. \& Kolb, T., Renewable power-to-gas: A technological and economic review. Renewable Energy, 85, pp. 1371-1390, 2016.

[3] Guilera, J., Morante, J.R. \& Andreu, T., Economic viability of SNG production from power and $\mathrm{CO}_{2}$. Energy Conversion and Management, 162, pp. 218-224, 2018.

[4] Gahleitner, G., Hydrogen from renewable electricity: An international review of powerto-gas pilot plants for stationary application. International Journal of Hydrogen Energy, 38(5), pp. 2039 - 2061, 2013.

[5] Antenucci, A. \& Sansavini, G., Extensive $\mathrm{CO}_{2}$ recycling in power systems via power-togas and network storage. Renewable and Sustainable Energy Reviews, 100, pp. 33-43, 2019.

[6] Fevre, C.N.L., The future of gas networks: Key issues for debate, Oxford Institute for Energy Studies, 2019. 
[7] Pellegrino, S., Lanzini, A. \& Leone, P., Greening the gas network - the need for modelling the distributed injection of alternative fuels. Renewable and Sustainable Energy Reviews, 70, pp. 266-286, 2017.

[8] Curto, D. \& Martin, M., Renewable based biogas upgrading. Journal of Cleaner Production, 224, pp. 50-59, 2019.

[9] Blanco, H., Nijs, W., Ruf, J. \& Faaij, A., Potential of power-to-methane in the EU energy transition to a low carbon system using cost optimization. Applied Energy, 232, pp. 323-340, 2018.

[10] Sibai, A.E., Rihko-Struckmann, L. \& Sundmacher, K., Synthetic methane from $\mathrm{CO}_{2}$ : Dynamic optimization of the Sabatier process for power-to-gas applications. Computer Aided Chemical Engineering, 37, pp. 1157-1162, 2015.

[11] Gorre, J., Ortloff, F. \& van Leeuwen, C., Production costs for synthetic methane in 2030 and 2050 of an optimized power-to-gas plant with intermediate hydrogen storage. Applied Energy, 253, paper 113594, 2019.

[12] Jeanmonod, G., Wang, L., Diethelm, S., Marechal, F. \& van Herle, J., Trade-off designs of power-to-methane systems via solid-oxide electrolyser and the application to biogas upgrading. Applied Energy, 247, pp. 572-581, 2019.

[13] Guilera, J., Andreu, T., Basset, N., Boeltken, T., Timm, F., Mallol, I. \& Morante, J.R., Synthetic natural gas production from biogas in a waste water treatment plant. Renewable Energy, 146, pp. 1301-1308, 2020.

[14] Collet, P., Flottes, E., Favre, A., Raynal, L., Pierre, H., Capela, S. \& Peregrina, C., Techno-economic and life cycle assessment of methane production via biogas upgrading and power-to-gas technology. Applied Energy, 192, pp. 282-295, 2017.

[15] Bailera, M., Lisbona, P., Romeo, L.M. \& Espatolero, S., Power-to-gas projects review: $\mathrm{Lab}$, pilot, and demo plants for storing renewable energy and $\mathrm{CO}_{2}$. Renewable and Sustainable Energy Reviews, 69, pp. 292-312, 2017.

[16] Saba, S.M., Muller, M., Robinius, M. \& Stolten, D., The investment costs of electrolysis - A comparison of cost studies from the past 30 years. International Journal of Hydrogen Energy, 43(3), pp. 1209-1223, 2018.

[17] Miltner, M., Makaruk, A. \& Harasek, M., Review on available biogas upgrading technologies and innovations towards advanced solutions. Journal of Cleaner Production, 161, pp. 1329-1337, 2013.

[18] Sustainable Energy Authority of Ireland (SEAI), Domestic fuels - Comparison of Energy Costs, 2019.

[19] U.S. Department of Energy (DOE), Hydrogen Production Tech Team Roadmap, USDRIVE, 2017.

[20] Saxe, M. \& Alvfors, P., Advantages of integration with industry for electrolytic hydrogen production. Energy, 32(1), pp. 42-50, 2007.

[21] Kato, T., Kubota, M., Kobayashi, N. \& Suzuok, Y., Effective utilization of by-product oxygen from electrolysis hydrogen production. Energy, 30(14), pp. 2580-2595, 2005.

[22] Sustainable Energy Authority of Ireland (SEAI), Energy in Ireland - 2018 Report, 2018.

[23] World Bank Group: Natural Gas Prices Forecast: Long Term 2018 to 2030. URL http:// comstat.comesa.int/ncszerf/natural-gas-prices-forecast-long-term-2018-to-2030-dataand-charts-Überprüfungsdatum2019-02-20 